\section{Memory of electroconvulsive shock as a function of intensity and duration*}

\author{
JAMES R. MISANIN, Susquehanna University, Selinsgrove, Pa. 17870 \\ NELSON F. SMITH, University of Rhode Island; Kingston, R.I. 02881 \\ and \\ RALPH R. MILLER, Brooklyn College of CUNY, Brooklyn, N.Y. 11210
}

Following multitrial active-avoidance training in a two-way shuttlebox, rats received a single electroconvulsive shock (ECS) of one of three intensities and six durations. Convulsed animals required more trials to relearn the task than they had taken in original learning, suggesting that ECS was an aversive stimulus. This effect first increased and then decreased with increasing ECS intensity. A similar, but weaker $(\mathrm{p}<.10)$, inverted U-shaped function was found for ECS duration. The inverted-U function is thought to be an interaction of the aversive stimulus properties and amnesic properties of ECS. The significance of memory of ECS surviving the amnesic properties of ECS is considered.

Recent studies using electroconvulsive shock (ECS) to probe the nature of memory have tended to use single ECS paradigms in order to avoid the aversive stimulus aspects attributed to multiple ECS but not to a single ECS (Hudspeth, McGaugh, \& Thomson, 1964). However, there is evidence that, at least in environments in which the $S$ has had considerable experience prior to ECS, even a single ECS has aversive properties (e.g, Lewis, Miller, \& Misanin, 1968; Misanin, 1966; Misanin \& Smith, 1964). The present study examines the effect of ECS intensity and duration upon the aversiveness of a single ECS.

The effect of these two independent variables on the degree of memory deficit induced by ECS has received considerable attention recently, with something less than a consensus being reached. The majority of studies have found that an increase in ECS intensity prolongs the posttraining interval of vulnerability (Hughes, Barrett, \& Ray, 1970; Miller, 1968; Pagano, Bush, Martin, \& Hunt, 1969; Ray \& Barrett, 1969). However, there are reports of ECS intensity having no effect upon the temporal gradient for amnesia (Paolino, Quartermain, \& Levy, 1969; Ray \& Barrett, 1969). Alpern \& McGaugh (1968) observed that increased ECS duration also prolonged the vulnerable period, contrary to the lack of an ECS-duration effect typically reported (Miller, 1968; Paolino, Quartermain, \& Miller, 1966). Assuming that the aversiveness of a noxious stimulus increases monotonically with stimulus intensity and duration, in a situation known to provide an aversive ECS effect (Misanin \& Smith, 1964), increases in ECS intensity or duration should prove progressively more

*This study was supported by USPHS Grants MH 07129 , MH 17207, and MH 17906. aversive, unless the frequently observed increasing gradient of amnesia rises more steeply than does the gradient of aversiveness, in which case ECS intensity and duration should yield inverted U-shaped functions for remembered aversiveness.

The current experiment uses essentially the multitrial active-avoidance paradigm of Misanin \& Smith (1964), in which a single ECS administered to the animal during the act of responding was shown to have an aversive effect. Both experiments of that study also employed groups receiving ECS while not performing the avoidancy response (AR). These groups failed to display any more response suppression than the pseudo-ECS Ss, indicating that the response suppression displayed by groups receiving ECS while making the AR cannot systemic effects produced by ECS. SUBJECTS

The Ss were 152235 - to 285 -g male albino rats of the Sprague-Dawley strain obtained from CAM Research Laboratories, Wayne, New Jersey. The animals were randomly assigned to 1 of 19 groups of eight Ss each. During the experiment, the rats were housed in individual wire-mesh cages and given free access to food and water.

\section{APPARATUS}

An automated shuttlebox designed for active avoidance training was modeled after Brush \& Knaff (1959). The box was $40 \mathrm{~cm}$ long, $14 \mathrm{~cm}$ wide, and $22.5 \mathrm{~cm}$ high and was housed in a soundproof chamber. The sides of the box were constructed of aluminum, the top of Plexiglas, and the floor of .23 -cm-diam stainless steel grids, spaced $2.25 \mathrm{~cm}$ apart center-to-center. The shuttlebox was divided into two identical compartments by an aluminum partition equipped with a $7.5 \times 7.5 \mathrm{~cm}$ top-hinged fiber door that permitted passage between be attributed to activity changes or other compartments. Photoelectric cells, located $7 \mathrm{~cm}$ from each side of the central partition and $2.5 \mathrm{~cm}$ above the grid floor, were operated by an animal's passage through the doorway. These photocells served to track the S's position at all times.

The CS in the present experiment was a 6-W light used in combination with a $10-\mathrm{Hz}$ $(80 \pm 1 \mathrm{~dB})$ clicker. The bulbs and clickers were mounted at the end of each compartment over the Plexiglas lid. The US was a $200-V$ scrambled shock, delivered to the grids by a fixed-impedance shock source with $150,000 \mathrm{ohms}$ in series with the rat.

The ECS source was a constant-voltage device, attached to the S's ears via shielded earclips coated with electrode paste. Voltage levels used were 75,150 , and $300 \mathrm{~V} \mathrm{rms}, 60 \mathrm{~Hz}$, corresponding to approximately 35,70 , and $140 \mathrm{~mA}$, respectively. Durations examined were .05 , $.20, .50, .75,1.00$, and $1.50 \mathrm{sec}$.

\section{PROCEDURE}

During avoidance training, the CS came on $30 \mathrm{sec}$ after the offset of the last reinforcement and continued for $5 \mathrm{sec}$, at the end of which the US was presented. All animals were trained to a criterion of 10 consecutive ARs. Those animals that did not reach this criterion in 80 training trials were discarded and replaced by animals that did meet the criterion. Following the last criterion trial, each rat had earclips attached and was returned to the apparatus for an additional trial. On this trial all animals received escapable, but unavoidable, CS plus US. Upon escaping through the door, the animals in each of the 18 groups received ECS of intensity and duration appropriate to their group designation, while the 19th group received pseudo-ECS (NECS).

Fifteen minutes after ECS or pseudo-ECS (sufficient time for the return of normal posture), each $\mathrm{S}$ was returned to the apparatus for retraining. Retraining trials were identical to original training trials. Despite the short ECS-relearning interval, no control group for systemically induced changes in activity were included in the present study, since Misanin \& Smith (1964) ran extensive activity controls in the identical apparatus $15 \mathrm{~min}$ after ECS and found no change in activity in this particular situation. A minimum of 50 retraining trials were run, and those $S s$ failing to achieve a criterion of 10 consecutive avoidance trials within these 50 retraining trials received additional retraining trials until this criterion was reached or a total of 100 retraining trials was given.

\section{RESULTS}

Mean number of trials to the last criterion trial in original training for each 


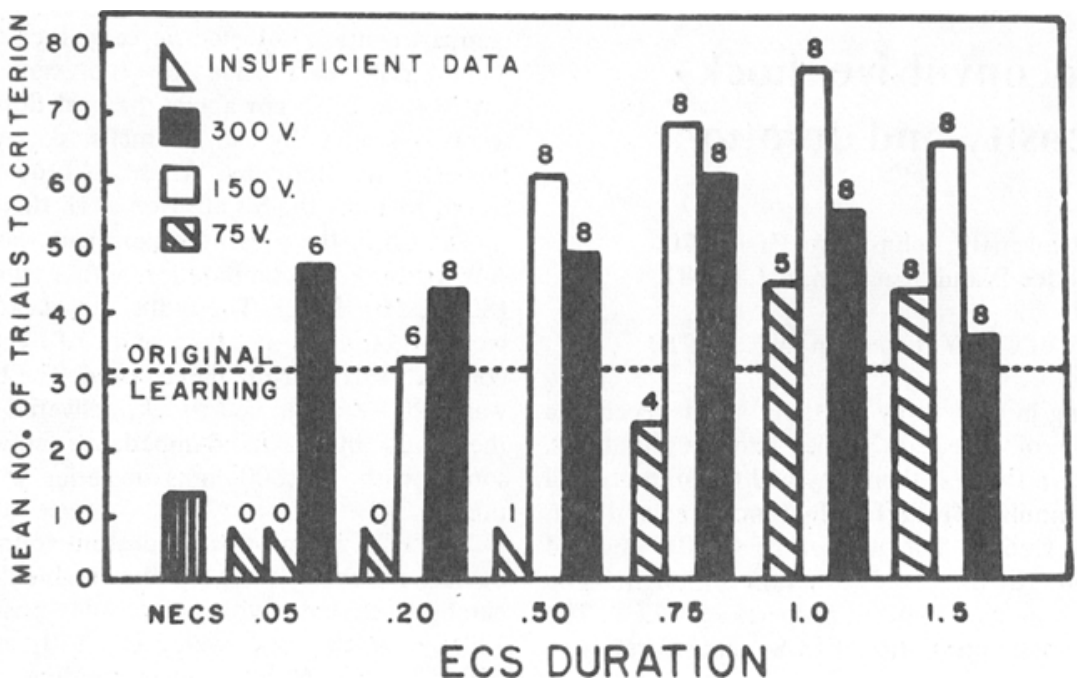

Fig. 1. Mean number of trials to the last of 10 consecutive avoidance responses during original learning for all animals (horizontal line) and during relearning as a function of ECS intensity (volts) and duration (seconds) for animals displaying full tonic-clonic convulsions (bars). Only the data from ECS groups in which four or more animals yielded complete convulsions are shown. The number of animals out of each group of eight is presented above the bar representative of each group.

group and all subsequent measures proved sufficiently normal to permit the use of parametric statistics. A 3 by 6 factorial analysis of trials to criterion in original learning found no group differences prior to treatment ( $\mathrm{ps}>.50$ ). The NECS group was equally undistinguished.

Numerous Ss, particularly those receiving low-intensity and short-duration ECS, failed to exhibit an extensor phase at the end of the tonic stage of their convulsions. Figure 1 includes the frequency of complete convulsions displayed by the eight Ss within each group. Although the number of Ss within any one group was too small to obtain meaningful statistics, given equal ECS intensity and duration there appeared to be a trend toward a smaller performance deficit in relearning for partial convulsion animals than for those displaying full convulsions. This observation is consistent with previous reports of attenuated consequences of ECS in unanesthesized animals failing to yield full convulsions (e.g., Miller \& Spear, 1969). In order to minimize possible ambiguities in interpretation, all $\mathrm{Ss}$ failing to yield complete convulsions were discarded. The resulting unequal group sizes were taken into account in subsequent analyses of variance (stated Fs and dfs are adjusted as prescribed by Winer, 1962).

An analysis of variance was applied to the mean number of trials to criterion in relearning for the 18 ECS groups (see Fig. 1). ECS intensity proved significant $(\mathrm{F}=4.26 . \quad \mathrm{df}=2 / 87 . \quad \mathrm{p}<.025) ; \quad$ ECS duration fell just short of significance at the .05 level $(\mathrm{F}=2.21, \mathrm{df}=5 / 87, \mathrm{p}<.10)$ : and the interaction was nonsignificant $(\mathrm{F}<1.00)$. Analysis of the number of avoidances in 50 relearning trials yielded essentially the same results. Two-tailed $t$ tests upon trials to criterion in relearning were used to determine the sources of significance. More trials were necessary for the $150-\mathrm{V}$ Ss than for the $75-\mathrm{V}$ Ss $(\mathrm{t}=2.62, \mathrm{df}=54, \mathrm{p}<.02)$; the feiver trials necessary for the $300-\mathrm{V}$ Ss than for the $150-\mathrm{V}$ Ss fell just short of significance at the .05 level $(\mathrm{t}=1.81, \mathrm{df}=82, \mathrm{p}<.10)$; and the difference between the $75-\mathrm{V}$ and the $300-\mathrm{V}$ Ss proved nonsignificant. No significant differences between different ECS durations were found, except that the .20 -sec animals required fewer relearning trials than did the .75 - and $1.00-\mathrm{sec}$ animals $(p<.05)$. Comparison of the NECS Ss' relearning scores to each of the ECS groups found all differences to be significant (all ps $<.05$ ), except for the 75-V.75-sec ECS group. An overall within-Ss comparison of trials to criterion in learning and relearning for all ECS Ss proved significant $(p<.001)$. The same comparison by groups yielded learning-relearning differences for none of the $75-\mathrm{V}$ groups. for all $150-\mathrm{V}$ groups between .50 and $1.5 \mathrm{sec}$ inclusively, for all $300-\mathrm{V}$ groups between .20 and $1.0 \mathrm{sec}$ inclusively, and for the NECS group (all ps $<.05$ ).

\section{DISCUSSION}

The present results show trials to criterion in relearning to be an inverted $\mathrm{U}$-shaped function of ECS intensity, and a similar. but nonsignificant trend is seen for ECS duration. Apparently intensity is a more powertul variable parameter of ECS than is duration. As most ECS groups not only failed to benefit from original leaming but also actually did significantly worse in relearning than in original learning, a purely amnesic view of ECS in this situation is untenable. Moreover, this impediment of relearning cannot be attributed to systemic effects of ECS and/or reduced activity. as Misanin \& Smith (1964) ran animals in the same apparatus in a similar experiment and the results excluded this possibility. The data may. however. be understood as the product of aversive stimulus properties of ECS that increase with intensity superimposed upon the amnesic consequences of ECS that also increase with intensity. The proportion of recently acquired memory vulnerable to ECS-induced amnesia is thought to increase with ECS intensity more rapidly than does the aversiveness of ECS. This view places ECS on a continuum starting with obviously painful. low-intensity subconvulsive shock applied to the ears. and is in contrast to the position that a sharp discontinuity exists between aversive and amnesic applications.

The point at which the amnesic properties override the aversive properties of a single ear shock is ordinarily below the convulsive threshold (Hudspeth. McGaugh. \& Thomson, 1964). However. after multitrial training, which apparently facilitates the acquisition of aversive associations with the environment. the aversive properties of ear shock are found to appear even above the convulsive threshold. These results are consistent with the aversive properties of ECS previously observed after multitrial training (Misanin. 1966: Misanin \& Smith. 1964). In a different apparatus, Lewis. Miller, \& Misanin (1968) found that prior exposure to the test environment without any training proved adequate to permit the aversive properties of a single ECS to appear above the convulsive threshold. However. this aversiveness was of insufficient magnitude to explain their familiarization effect. Possibly the pretraining exposure in that study and the extensive training in the present study served in a similar fashion to either enhance associations with the aversive aspects of ECS or reduce ECS-induced amnesia for these associations. Miller (1970) presents evidence supporting the latter of these possibilities. The aversiveness of a single ECS demonstrated in the past (Lewis. Miller, \& Misanin. 1968: Misanin, 1966; Misanin \& Smith. 1964) and the present study argue for the 
inclusion of the appropriate control groups in ECS experiments.

The observed aversiveness of a single ECS is to be logically expected given the generally accepted aversiveness of multiple ECS (Hudspeth, McGaugh, \& Thomson, 1964). If the sole effect of ECS was amnesic, after each convulsion the $\mathrm{S}$ should appear naive. That aversiveness results from repeated ECSs strongly suggests that fear of ECS-associated cues is cumulative starting with the first ECS.

The theoretical point of this study is that, at least in situations to which the $S$ has been extensively exposed, ECS fails to prevent the formation of a memory of itself. As the temporal interval between onset of the aversive stimulus (ECS in this case) and ECS is obviously nil, the conclusion must be drawn that "memories" that have had no time at all to consolidate can survive ECS. This is equivalent to saying that unconsolidated memories are not necessarily rendered unavailable by ECS. Lewis, Miller, \& Misanin (1969) reported that after pretraining familiarization with the apparatus, ECS could not interfere with a 0.5 -sec-old memory. They accepted the conventional view that ECS acts selectively upon unconsolidated memories and concluded that consolidation could reach an initial first stage of completion in-less than $0.5 \mathrm{sec}$. The present data suggest that ECS is an inadequate probe to separate recently received information from consolidated memories.

\section{REFERENCES}

ALPERN, H. P., \& MCGAUGH, J. L. Retrograde amnesia as a function of duration of electroshock stimulation. Journal of Comparative \& Physiological Psychology, $1968,64,265-269$.

BRUSH, F. R.. \& KNAFF, P. R. A device for detecting and controlling automatic programming of avoidance conditioning in a shuttlebox. American Psychologist, 1959, 72, 275-278.

HUDSPETH. W. J., McGACGH, J. L., \& THOMSON, C. W. Aversive and amnesic effects of electroconvulsive shock. Journal of Comparative \& Physiological Psychology, $1964,57,61-64$.

HUGHES, R. A., BARRETT, R. J., \& RAY, O. S. Retrograde amnesia in rats increases as a function of ECS-test interval and ECS intensity. Physiology \& Behavior, 1970, 5, $27-30$.

LEWIS, D. J., MILLER, R. R., \& MISANIN, J. R. Control of retrograde amnesia. Journal of Comparative \& Physiological Psychology, $1968,66,48-52$.

LEWIS, D. J., MILLER, R, R., \& MISANIN, J. R Selective amnesia in rats produced by electroconvulsive shock. Journal of Comparative \& Physiological Psychology. 1969, 69. 136-140.

MILLER, A. J. Variations in retrograde amnesia with parameters of electroconvulsive shock and time of testing. Journal of Comparative \& Physiological Psychology. 1968, 66. 40-47.
MILLER, R. R. Effects of environmental complexity on amnesia induced by electroconvulsive shock in rats. Journal of Comparative \& Physiological Psychology, 1970,71, 267-275.

MILLER, R. R., \& SPEAR, N. E. Memory and the extensor phase of convulsions induced by electroconvulsive shock. Psychonomic Science, $1969,15,164-166$.

MISANIN, J. R. Role of fear in the facilitative and inhibitory effects of electroconvulsive shock. Joumal of Comparative \& Physiological Psychology, 1966, 61, 411-415.

MISANIN, J. R., \& SMITH, N. F. Role of response-linked fear in the effects of a single ECS on an avoidance response. Journal of Comparative \& Physiological Psychology, 1964, 58, 212-216.

PAGANO, R. R., BUSH, D. F., MARTIN, G., \& HUNT, E. B. Duration of retrograde amnesia as a function of electroconvulsive shock intensity. Physiology \& Behavior, 1969, 4, 19-21.

PAOLINO, R. II., QLARTERMAIN, D., \& LEVY. H. M. Effect of electroconvulsive shock duration on the gradient of retrograde amnesia. Physiology \& Behavior, 1969, 4, 147-149.

PAOLINO, R. M., QUARTERMAIN, D., \& MILLER, N. E. Different temporal gradients of retrograde amnesia produced by carbon dioxide anesthesia and electroconvulsive shock. Journal of Comparative \& Physiological Psychology, 1966, 62, 270-274.

RAY, O. S., \& BARRETT, R. J. Disruptive effects of electroconvulsive shock as a function of current level and mode of delivery. Journal of Comparative \& Physiological Psychology, $1969,67,110-116$.

WINER, B. J. Statistical principles in experimental design. New York: McGraw-Hill, 1962.

\title{
The effects of shock intensity and intertrial interval duration on the operant level of a shuttle-avoidance response
}

\author{
GEORGE A. CICALA, RONALD R. ULM, and DAVID R. DREWS \\ University of Delaware, Newark, Del. 19711
}

The factorial assessment of the effects of shock intensity and ITI on the unreinforced occurrence of shuttle responses showed that these variables affect initial response rate in the same way as they have been shown to affect shuttle-avoidance acquisition. It was also shown that CS introduction uniformly enhanced operant-avoidance rates. It was concluded that CS introduction, long ITIs, and low shock intensities each enhance response probability and, consequently, increase the likelihood of response reinforcement.

In a first attempt to discover factors determining the probability of unreinforced responses in a shuttle-avoidance situation, the intensity of the UCS and the duration of the intertrial interval (ITI) were selected for study. Moyer \& Korn (1964), Levine (1966), and Cicala \& Kremer (1969) have uniformly shown that shuttle-avoidance learning is inversely related to shock intensity. While Murphy \& Miller (1956) and Levine \& England (1960) have shown that shuttle-avoidance learning improves with increases in ITI duration, Brush (1962), in a complete assessment of this parameter, found improvement up to $5 \mathrm{~min}$.

Since the acquisition of a shuttle response must depend upon the initial probability of occurrence of that response, it is reasonable to assume that if different shock intensities and different ITIs produce differences in unreinforced response rate, these differences may account, either wholly or in part, for the results of parametric studies of shuttle-avoidance learning. The present study was done to test this hypothesis.

\section{SUBJECTS}

Thirty-two male Wistar rats, $90-110$ days old, were used.

\section{APPARATUS}

A test cage constructed entirely of stainless steel grids spaced $1 / 2$ in. apart in a Plexiglas frame, $9 \times 7 \frac{1}{2} \times 6 \frac{1}{2}$ in. was used. All of the grids were wired for shock. A speaker directed at the test cage was mounted in the top of a sound-attenuating chamber enclosing the test cage. A variable-output $150-\mathrm{K}-\mathrm{ohm}$ fixed-impedance shock source (Campbell \& Masterson, 1969) provided the shock stimuli. Interruptions of a photocell beam bounced across the width of the test cage recorded crossings.

\section{PROCEDURE}

Ss were divided into four groups and were assigned to a 2 by 2 factorial matrix varying shock intensity, $120 \mathrm{~V}$ vs $300 \mathrm{~V}$, and ITI, $35 \mathrm{sec}$ vs $5 \mathrm{~min}$. Each $\mathrm{S}$ was placed in the test cage and, after $2 \mathrm{~min}$, was presented with 50 inescapable, unavoidable presentations of a $12-\mathrm{sec}, \quad 80-\mathrm{dB}$, white-noise CS, the last $2 \mathrm{sec}$ of which was paired with an overlapping 2 -sec electric shock.

Crossings measured by photocell interruptions served as the index of unreinforced avoidance responding. This measure was taken during the 10 -sec period prior to CS onset (pre-CS) and during the initial $10 \mathrm{sec}$ of the CS period (CS). 